DOI: $10.17058 /$ rjp.v5i2.5814

\title{
FAMÍLIA E USO DE CRACK: (RE)INSCREVENDO SENTIDOS NO CENÁRIO SOCIAL CONTEMPORÂNEO
}

\author{
Bruna Rocha de Araujo ${ }^{1}$ \\ Giórgia Reis Saldanha ${ }^{2}$ \\ Mauricéia Eloisa Moraes ${ }^{3}$ \\ Emanueli Paludo ${ }^{4}$ \\ Edna Linhares Garcia ${ }^{5}$
}

\begin{abstract}
RESUMO
Este artigo apresenta reflexões acerca das relações familiares e o uso de drogas a partir da análise dos dados da pesquisa "A realidade do crack em Santa Cruz do Sul”. Trata-se da análise dos sentidos produzidos nos discursos de 100 usuários de crack e de 100 familiares de usuários de crack, contatados por meio de serviços de saúde. A compreensão da família como (re)invenção social nos contextos histórico, político e econômico contemporâneos, levou-nos a problematizar os paradoxos enunciados nos discursos acerca da relação uso de crackfamília, ora identificando-a como responsável pelo uso de drogas, ora apontando-a como vítima do usuário de crack, o qual é tomado como destituído de qualquer controle sobre sua vida. Decorre daí a compreensão de que o contexto familiar, comunitário e social não seja apto para cuidar do usuário de crack. Assim, colocamos em pauta a necessidade de problematizar a idealização da família, bem como os desafios da Reforma Psiquiátrica no cuidado aos usuários de álcool e outras drogas, a fim de compreender uma realidade que está posta, para a qual não resta saída senão a internação e o isolamento do usuário.
\end{abstract}

Palavras-chave: Crack. Família. Cuidado. Reforma Psiquiátrica.

\begin{abstract}
This article shows the relationships between drug users and their families from research data "A realidade do crack em Santa Cruz do Sul." This analysis based on reports from 100 crack users and 100 relatives of crack users through healthcare services. The family comprehension as a tool to (re) invetion in historical, political and economic contexts, leed us to question the paradoxes about the relationship between crack user and their family, sometimes identifying it as responsible for the drugs consume or indicated as the victim of crack user, in which is considered without any control over your life. From this point the understanding that family, community and social context is not able to take care of crack users by his one. Therefore, we put forth the need to identify the family idealization, as well as the challenges of Psychiatric Reform in care to users of alcohol and other drugs, in order to understand a reality in which there is no other choice but put them in intensive care for treatment.
\end{abstract}

Keywords: Crack. Care. Family. Psychiatric Reform.

\footnotetext{
${ }^{1}$ Psicóloga integrante da pesquisa A realidade do crack em Santa Cruz do Sul. <brunara.tk@gmail.com>

${ }^{2}$ Aluna do Curso de Psicologia da Universidade de Santa Cruz do Sul - UNISC. <girsaldanha@gmail.com>

${ }^{3}$ Aluna do Curso de Psicologia da Universidade de Santa Cruz do Sul - UNISC. <maurieloisa@ hotmail.com>

${ }^{4}$ Psicóloga integrante da pesquisa A realidade do crack em Santa Cruz do Sul. <manuulely@gmail.com>

${ }^{5}$ Professora do Departamento de Psicologia na Universidade de Santa Cruz do Sul - UNISC. <edna@ unisc.br>
} 


\section{INTRODUÇÃO}

O aumento significativo das preocupações com o uso de crack - medido pela ampliação da produção científica, o desenvolvimento de políticas públicas, planos e programas de prevenção e cuidados ao usuário, a constante oferta de cursos, seminários, congressos, além do frequente enfoque midiático - associado às diversas complexidades provenientes do uso e abuso de substâncias lícitas e ilícitas, suscitam a urgência de reflexões comprometidas e eticamente responsáveis de diversos setores da sociedade (saúde, assistência social, cultura, justiça, economia) que se articulam a este contexto, no cenário contemporâneo.

O Relatório Brasileiro sobre Drogas destaca a existência de um "grave impacto que o uso abusivo de substâncias psicoativas tem em áreas relevantes da realidade brasileira, como são a saúde e o trabalho, com graves repercussões para a sociedade como um todo" (DUARTE, et. al, 2009, p. 356), da mesma forma que aponta a necessidade de discutir a problemática do uso abusivo de drogas, que há pouco tempo era uma questão negligenciada.

Neste sentido, Zeferino et. al (2015) confirmam os apontamentos sobre a intensidade das discussões da temática, chamando atenção para a complexidade estatística pertencente à contemporaneidade:

\footnotetext{
A atualidade internacional revela uma ascensão no uso de drogas ilícitas com uma cifra de 230 milhões de pessoas com idade entre 15 e 65 anos de idade. Com relação ao consumo de drogas lícitas, estima-se em mais de 200 milhões de consumidores de álcool e 700 milhões de pessoas fazem uso de tabaco em todo o mundo (2015, p. 126).
}

No município de Santa Cruz do Sul, constatou-se, a partir de pesquisa realizada no ano de 2010 pelo grupo da pesquisa "A Realidade do Crack em Santa Cruz do Sul”, em sua $1^{\text {a }}$ Etapa, que a idade de maior concentração do número de usuários está entre 19 e os 32 anos de idade, ou seja, no início da idade adulto jovem, sendo que "o inicio do uso de drogas se deu no período da adolescência, entre 10 e 15 anos (62\%) e entre 16 e 21 anos de idade (23\%) (Garcia et al, 2012, p. 85), fator este que permeia um dos determinantes da urgência e da necessidade de discussões sobre a temática na Região.

O cenário de inquietação que se expandiu em diversos espaços da sociedade, retrata diferentes contextos sociais e abrange determinantes variados e peculiares relacionados ao consumo de substâncias líticas e/ou ilícitas. Ou seja, o uso de drogas sempre permeou a história da humanidade, por motivos distintos e variados, cada contexto cultural de um dado momento histórico entendeu e utilizou a droga com um significado particular. Entretanto, o aumento da proporção do consumo que se apresenta na atualidade requer um olhar abrangente 
e contemplativo da dinâmica social/familiar envolvida nos aspectos que estão implicados na relação de dependência com a droga ou drogadição.

Desta forma, ao considerar a diversidade de fatores que se relacionam ao uso de drogas e o contexto histórico que sustenta as relações contemporâneas, este estudo problematiza o paradoxo enunciado nos discursos acerca da relação uso de crack-família, ora identificando-a como responsável pelo uso de drogas, ora apontando-a como vítima do usuário de crack, o qual é tomado como destituído de qualquer controle sobre sua vida.

Os dados utilizados neste estudo fazem referência a $2^{\mathrm{a}}$ etapa da pesquisa "A Realidade do Crack em Santa Cruz do Sul" desenvolvida no município desde o ano de 2010, com o objetivo de produzir conhecimento e intervir junto à comunidade nos aspectos relacionados à drogadição.

A partir das narrativas dos sujeitos entrevistados na pesquisa, observou-se uma ambivalência nos discursos, o que fez emergir uma necessidade de (re)pensar a atuação da família e da comunidade nos cuidados voltados ao usuário de álcool e outras drogas, a fim de compreender uma realidade que está atravessada diariamente pela drogadição. Através das entrevistas foi possível alcançar uma breve aproximação com a vida destes sujeitos que, para além de usuários de drogas, evidenciam outras relações, em especial, com seus familiares. Esta vivência suscitou no grupo inquietações e, consequentemente, problematizações sobre a idealização da família, bem como fez emergir a necessidade de discutir as relações entre o usuário de drogas, suas famílias e o cenário contemporâneo.

\section{REVISÃO BIBLIOGRAFICA SOBRE INSTITUIÇÃO FAMILIA}

Primeiramente, consideramos que é importante pontuar nosso entendimento sobre os modos de se constituir família na sociedade. Desta forma, enfatizamos o que as autoras Narvaz e Koller (2006) destacam:

\footnotetext{
a família não é algo biológico, algo natural ou dado, mas produto de formas históricas de organização entre os humanos. Premidos pelas necessidades materiais de sobrevivência e de reprodução da espécie, os humanos inventaram diferentes formas de relação com a natureza e entre si. As diferentes formas de organização familiar foram, portanto, inventadas ao longo da história (p. 50).
}

A partir deste entendimento, pode-se dizer que a família passou por diferentes configurações e modos de vivenciar suas relações ao longo dos anos. Nas sociedades chamadas "primitivas" a organização da família se dava em torno da figura materna, 
especialmente pela valorização da reprodução e propagação da espécie humana. Neste espaço, as relações sexuais não eram praticadas nos preceitos da monogamia e os papéis sociais de ambos os sexos eram distribuídos sem grande rigidez de gênero.

Posterior a isso, com a descoberta da agricultura as relações de trabalho foram se modificando, de forma que as mulheres passaram a cuidar dos filhos e do cultivo de alimentos enquanto os homens se responsabilizavam pela caça e pela pesca. Neste momento, instauravase também a monogamia, especialmente para garantir que os filhos do casal tivessem direito assegurado à herança da família.

Todavia, a instituição família teve primórdios na Roma Antiga, na qual centrava-se a figura do homem, enquanto a mulher apenas aparecia à sombra do contexto familiar. Neste sentido, o homem detinha poder absoluto sobre os filhos e sobre a esposa. Até este período, não há registros acerca da existência de um "sentimento de família", o qual só foi constituído e expressado posteriormente (AIRÈS, 1981).

As pesquisas de Ariès (1981) ainda apontam que é a partir do século XV, com a ascensão da burguesia, que as relações e os sentimentos de família se transformam, sobretudo, pela preocupação com a educação das crianças. Os filhos até então eram enviados a outras famílias que assumiam a responsabilidade pela transmissão de conhecimento sobre tarefas comuns a vida e mesmo as atividades profissionais.

Outra mudança deste período é a frequência das crianças na escola que passa a assumir importância no discurso moral e religioso, estes compreendiam a educação formal como instrumento de normatização, de treinamento civil e de iniciação das crianças na vida moral e social, com afastamento da vida dos adultos. Da mesma forma, as mulheres passaram a assumir papel central nos cuidados e na educação dos filhos.

Nesse sentido, "a família deixou de ser apenas uma instituição do direito privado para transmissão dos bens e do nome, e assumiu uma função moral e espiritual, passando a formar os corpos e as almas" (ARIÈS, 1981, p. 277).

Esta preocupação com o cuidado e a formação das crianças aponta para o fechamento da família em torno de si mesma, na medida em que a família moderna retira suas crianças da vida comum e, assim, grande parte do tempo e atividades dos adultos se volta para o âmbito familiar. Ariès (1981) destaca que "o cuidado dispensado às crianças passou a inspirar sentimentos novos [...] o sentimento moderno da família", sendo este sentimento baseado numa lógica de organização da família nuclear (ARIÈS, 1981, p. 278).

Embora seja possível apontar mudanças na configuração familiar, a discussão amplia-se para além desta dimensão, tendo em vista que a representação da família 
contemporânea ainda é padronizada no modelo nuclear em que pai, mãe e filhos constituem o núcleo central da instituição família, e deste modo, aquela família que apresenta uma configuração distinta passa a ser entendida como "família desestruturada" e como produtora de adoecimento.

É justamente sobre estes processos de culpabilização e/ou responsabilização da família pelo uso de drogas de algum de seus membros e pelo seu cuidado, que pretendemos discutir, compreendendo este como um processo que excluí diversos elementos sociais da dinâmica das relações familiares. Ampliaremos o debate em torno da questão na discussão dos resultados.

\section{METODOLOGIA}

A pesquisa A Realidade do Crack em Santa Cruz do Sul obteve a aprovação do Comitê de Ética em Pesquisa (CEP) da Universidade de Santa Cruz do Sul (UNISC), sob o n ${ }^{\circ}$ de inscrição 2527/10. O levantamento de dados da pesquisa se deu nos anos de 2010 e 2011, através de entrevistas semiestruturadas com 100 usuários de crack e 100 familiares de usuários.

As pessoas entrevistadas foram contatadas por intermédio de instituições parceiras, serviços públicos e conveniados de saúde que atendiam usuários de crack e seus familiares: Estratégia de Saúde da Família (ESF), Centro de Atenção Psicossocial infanto-juvenil (CAPSi), Centro de Atenção Psicossocial para Álcool e Drogas (CAPSAD), Comunidade Terapêutica, hospitais de referência e consultórios particulares.

As entrevistas realizadas nestes locais foram individuais e se organizaram como um espaço de diálogo entre entrevistador e entrevistado, com base em um roteiro semiestruturado, com anotações e gravação da entrevista, conforme autorização do entrevistado a partir da assinatura do termo de consentimento livre e esclarecido.

As entrevistas foram transcritas e numa primeira etapa submetidas à análise de dados quantitativos que se referiam principalmente ao contexto social, econômico e familiar dos entrevistados, já apresentado em outras publicações (GARCIA, et. al, 2012; ARAÚJO, GARCIA, ZACHARIAS, 2013; GARCIA et. al., 2013(a); GARCIA, ARAÚJO, ZACHARIAS, 2013(b).

Neste artigo, serão apresentados alguns resultados obtidos na segunda etapa da pesquisa a partir da análise qualitativa dos sentidos produzidos nos discursos dos familiares envolvendo o uso do crack e outras drogas. Cabe destacar que os sentidos são construções 
coletivas estabelecidas no seio das relações sociais, que são históricas e culturalmente localizadas (SPINK, 2000).

Segundo Spink (2000), o processo de análise qualitativa sustenta-se na escuta e na leitura das entrevistas no espaço de discussão constituído pelo grupo de pesquisadores. Este processo inicial possibilita constituir os marcadores relevantes presentes nas narrativas, construir reflexões e hipóteses interpretativas. Este encontro dos pesquisadores com a realidade dos usuários de crack e seus familiares permitiu escolher, para analisar as práticas discursivas, a perspectiva teórico-metodológica da produção de sentidos no cotidiano afiliada ao construcionismo social.

Tal dimensão de análise possibilita realizar uma leitura dos fenômenos a partir da perspectiva das construções sociais. Nesse sentido, as práticas discursivas se constituem nas rupturas e permanências de certos sentidos na sociedade, processo que ocasiona atravessamentos, tensões, transformações/semelhanças e reproduções, particularidades/diversidades e universalidades/semelhanças nos sentidos dos fenômenos sociais (SPINK, 2000). Isto aponta para a dinamicidade das transformações históricas que podem ser tomadas como fendas, nas quais processos de mudança se agenciam.

Deste modo, a escrita desse trabalho refere-se a aproximações com uma temática sempre em deslocamento/mudança. Conhecimentos produzidos com esta metodologia já estão socializados em trabalhos anteriores (GARCIA et al. 2013(a); GARCIA et al. 2013(b); ARAÚJO, ZACHARIAS e GARCIA, 2013).

\section{DISCUSSÃO DOS RESULTADOS}

\subsection{Reflexões Sobre Privatização da Família no Contexto do Uso de Drogas}

Em relação ao universo dos familiares entrevistados, deparamo-nos com a maioria composta por mulheres (82\%), em geral mães de usuários de crack, que tinham baixo nível de escolaridade e que estavam inseridas em situações de trabalho informais ou precárias em relação aos direitos trabalhistas e condições de trabalho.

As mulheres relatavam em suas experiências de vida, questões relacionadas à desigualdade social e de gênero, histórias marcadas por preconceito e violência. Mesmo tendo ingressado no mercado de trabalho e cumprindo diariamente altas cargas horárias, elas eram as principais responsáveis pelos cuidados e pela educação dos filhos.

Reconhecemos que esta relevância está atravessada pelo fato de que as entrevistas foram realizadas com famílias de baixa renda, mas também atentamos para recorrência de 
encontrarmos mais mulheres nos serviços de saúde, acompanhando seus familiares e/ou buscando apoio para si, refletindo o lugar da mulher-cuidadora e responsável pelos filhos.

Consideramos importante, neste sentido, refletir sobre os atravessamentos sociais, políticos, econômicos e culturais na organização dos modos de ser família e os modos de se relacionar no âmbito intrafamiliar; chamamos a atenção ao fato de que estas mulheres, por exemplo, assumiam um importante lugar como cuidadoras de seus familiares usuários de crack, tomando para si a responsabilidade de dar respostas às complexas problemáticas familiares, bem como, descrevendo as diversas mudanças pelas quais necessitam se adaptar frente as diferentes demandas envolvidas na situação.

No questionamento: "O que mudou na sua vida após essa situação de dependência com o crack?" é importante destacar a resposta de uma das entrevistadas, que descreve o processo complexo de mudança implicado no cotidiano da família e na dinâmica da vida pessoal dela enquanto cuidadora.

“Mudou tudo, porque a gente não tem mais paz, descanso né, daqui a pouco bem, depois não sabe como ele vai tá. Mudou tudo na nossa casa na nossa vida. O que a gente tinha antes a gente não tem agora. Porque a gente não sabe o que vai acontecer daqui um pouco né?" (Trecho da entrevista com Amália ${ }^{6}$, aposentada, 56 anos, familiar de usuários de crack).

Esse mesmo modo de compreender a problemática em relação ao uso de drogas como de responsabilidade familiar, é encontrado nas políticas públicas brasileiras que tem tomado um ideal de núcleo familiar como base de investimento, como espaço privado de proteção social. Nesse sentido, diversos autores têm apontado para uma espécie de estratégia do Estado em apostar na família como o lugar do cuidado, retraindo o seu papel em garantir os direitos sociais e civis e a proteção social em consonância com os ideais neoliberais e os investimentos do capital (SCHEINVAR, 2006; RODRIGUES et al., 2012; CAVALCANTI, VIEIRA, 2011).

Em relação ao uso de drogas no contexto em que os familiares estão inseridos, em 2003 a Política do Ministério da Saúde para a Atenção Integral a Usuários de Álcool e Outras Drogas passou a compreender como fator de risco um "padrão disfuncional de família", de forma que a ausência paterna se configurava como uma influência negativa. Desta forma, esta política destacava que

\footnotetext{
${ }^{6}$ Nome fictício.
} 


\begin{abstract}
o uso de álcool e outras drogas pelos pais é um fator de risco importante, assim como a ocorrência de isolamento social entre os membros da família. Também é negativamente influente um padrão familiar disfuncional, bem como a falta do elemento paterno. São considerados fatores de proteção a existência de vinculação familiar, com o desenvolvimento de valores e o compartilhamento de tarefas no lar, bem como a troca de informações entre os membros da família sobre as suas rotinas e práticas diárias; o cultivo de valores familiares, regras e rotinas domésticas também deve ser considerado, e viabilizado através da intensificação do contato entre os componentes de cada núcleo familiar (BRASIL, 2003, p. 32).
\end{abstract}

No entanto, a partir do realinhamento da Política Nacional sobre Drogas (PNAD) em 2008, houve uma maior ênfase para as dinâmicas familiares no sentido de torná-las fator de proteção e não de culpabilização. Desta forma, uma discussão referente aos modelos de vida familiar se faz imprescindível, já que o fato de atribuir culpa à família pelos caminhos percorridos pelos usuários de drogas desvia o olhar biopsicossocial envolvido no processo e, como consequência, causa danos e sofrimento a partir de sentimento de culpa a quem vivencia as relações do usuário no contexto das drogas (BRASIL, 2008).

Não se trata de questionar a família como parte da constituição do sujeito e das relações que ele possa estabelecer com a droga, mas sim de atentar para o fato de que a família distinta do modelo tradicional nuclear não condiciona o uso por um de seus membros. Desta forma, mostra-se importante considerar que a família é envolvida pelos meios sociais que a cercam e assume com isso uma configuração que de todo modo, também é caracteristicamente social. Segundo Scheinvar (2006),

a família é uma relação política e, como tal, implicada em processos de lutas e forças
que produzem o social. O chefe de família, no entender de Donzelot (1980), é uma
figura sociopolítica com a atribuição de garantir no interior desse núcleo a ordem
vigente. Função assentada em um paradoxo: de um lado, a estrutura produtiva
capitalista não está associada à concentração familiar, como ocorre em espaços de
economia servil; de outro, o desmembramento de um cotidiano construído a partir
de laços comunitários coloca a família como o agente político privilegiado para a
garantia da ordem. A família, que é um âmbito privado, é esquadrinhada pelo social,
em nome da ordem pública. (SCHEINVAR, 2006, p. 51).

Nesta perspectiva, entendemos que não há como individualizar e privatizar o uso de drogas, compreendendo que a família se organiza pelos modos de viver e de se relacionar produzidos socialmente, inclusive no que tange a estrutura familiar com base na sua singularidade.

As famílias apontadas como "culpadas" pelo uso de drogas de um familiar e os usuários ocupando um lugar de marginalidade, ambas são responsabilizadas por algo que é da ordem dos fenômenos sociais complexos, num processo de retração do Estado e das políticas 
públicas em um cenário capitalista. Empurrada a problemática para o âmbito familiar e individual (deslocado do contexto social), muitas vezes não se encontram recursos para abordagem de familiares e usuários de crack na dimensão do cuidado em saúde mental.

\subsection{Reflexões Sobre Culpabilização}

"Não sei onde eu errei, eu nunca deixei faltar nada, acho que dei demais liberdade" (Trecho da entrevista com Ana ${ }^{7}$, aposentada, 56 anos, familiar de usuários de crack).

É sobre falas semelhantes a esta, carregada de culpa e medo, que discorremos neste tópico. No contexto das entrevistas, identificamos nas narrativas dos familiares de usuários uma autoculpabilização frente ao uso de drogas de algum membro da família. Destacamos a importância do olhar sobre o sujeito e seus familiares que carregam culpa e sofrimento ao longo do uso de crack. Nesta lógica, é notório que as famílias se percebam e sejam percebidas, inclusive pela rede pública de saúde, deslocada da complexidade de elementos envolvidos no contexto do uso de drogas, especialmente aqueles relacionados ao Estado e as práticas de políticas públicas inter-relacionadas nas produções da sociedade capitalista.

O fato é que a culpa que acomete o familiar do usuário constitui-se em um discurso que canaliza para a família a responsabilidade pelo uso de drogas de um de seus membros, por vezes deslocando a discussão acerca dos modos de se relacionar contemporâneos. Além disso, torna-se necessário colocar em questão o esvaziamento das discussões acerca das responsabilidades do Estado em relação às políticas sociais e econômicas, que tem conformado modos de viver, os quais estão relacionados ao uso de drogas. Também é necessário reafirmar a necessidade de políticas de prevenção de uso de drogas e promoção de saúde. Segundo Cavalcanti e Vieira (2011),

(...) no que tange a família, vê-se na literatura científica a disseminação de visões que reforçam a culpabilização deste núcleo pelo consumo de drogas dos seus membros, valorizando, muitas vezes, na dinâmica familiar os aspectos subjetivos considerados conflituosos e, por isso impulsionadores diretos do uso de drogas destes membros. (2011, p. 03)

Como abordado acima, entendemos que mudanças sociais, culturais e econômicas contribuíram para a transformação da configuração social e familiar ao longo dos anos. Mas atentamos para o fato de que estas mudanças, em determinados momentos, aparecem nos

\footnotetext{
${ }^{7}$ Nome fictício.
} 
discursos científicos, jornalísticos e do senso comum, como motivo para a inserção do indivíduo no contexto das drogas. O fato é que, ora a família é vista como essencial cuidadora da saúde de seus integrantes, e ora é percebida como motivação para o uso de drogas, especialmente quando mudanças na diversidade dos modelos tradicionais de família são tidas como patológicos, apontados como um fator ou justificativa para o uso de drogas.

Culpar e apontar a família como a responsável por uma espécie de falha no cuidado de seus membros parece refletir justamente a dinâmica social contemporânea, onde usuários de drogas são representantes de uma cultura de consumo e a toxicomania um sintoma social de uma sociedade mercadológica que busca o prazer associado ao consumo (MELMAN, 1992; CONTE, 2003).

O uso de crack se articula a "uma conjuntura marcada pelo desemprego estrutural, pela 'dilapidação' de direitos sociais, precarização das relações de trabalho, privatizações, e, em consequência, acirramento do quadro de desigualdades sociais" (CAVALCANTI e VIEIRA, 2011, p. 04).

No decorrer da análise dos dados da pesquisa, o fator de autoculpabilização aparece com frequência, especialmente nas afirmações relacionadas à configuração familiar distinta do modelo tradicional. Isto é, o familiar aponta que o fato da família ter uma configuração distinta do modelo tido como "correto" contribui significativamente para o envolvimento de seus membros no uso de drogas, como consta na fala de Beatriz ${ }^{8}$, familiar de usuário de crack, participante da pesquisa que ao ser questionada sobre o que motivou o uso de drogas, responde:

"Eu acho a estrutura da família fraca. Eu me separei do pai dele, quando ele tinha 12 anos. Aí ele ficou muito à vontade, porque eu tinha que trabalhar e sustentar os dois porque eu fiquei sozinha. Aí ele ficou assim, na companhia do tio, na companhia do vô, e daí ele ia na escola e não conseguia estudar, eu não tinha muita paciência de conversar, de falar e ele sempre foi uma criança muito revoltada (...)”.

É perceptível o sofrimento que a entrevistada expressa no decorrer da fala, o que nos motivou a repensar e problematizar aspectos de cuidado com os usuários e também com o sistema familiar. No estudo literário desenvolvido por Schenker e Minayo (2004), as autoras concluem que

a grande contribuição resultante da discussão desses diversos estudos é a comprovação da importância da família para a formação e o desenvolvimento do uso

\footnotetext{
${ }^{8}$ Nome fictício.
} 
abusivo de drogas. Como consequência irrefutável, há necessidade de se tratar o sistema familiar para a transformação da adicção em produção de saúde. A questão das drogas invade múltiplos contextos que, conforme bem apontam os artigos, têm de ser envolvidos na abordagem do jovem. (, p. 657).

Neste sentido, articulam-se discursos que envolvem o uso de crack e a família, ora a identificando como responsável pelo uso de drogas de um de seus membros, ora como vítima do próprio usuário, tido como sujeito perigoso, destituído do controle absoluto da sua vida. E, é neste cenário que decorre a compreensão de que o contexto familiar, social e comunitário não estaria apto a praticar o cuidado com o usuário. Isto demanda uma importante análise, pois a partir do momento em que se entende que estas instâncias não produzem o cuidado, a internação e o isolamento passam a ser entendidos como únicas formas de cuidado possível.

A família que se modifica e se configura de tantas formas na sociedade contemporânea requer um olhar para além da culpa, ou seja, que nela sejam consideradas as suas necessidades e a sua potência perante as mudanças sociais e culturais que a atravessam e a configuram enquanto um sistema.

\section{CONSIDERAÇOES FINAIS}

$\mathrm{O}$ aumento do enfoque sobre o uso de crack no Brasil demanda reflexões que possibilitem repensar as práticas de Saúde Coletiva e da Reforma Psiquiátrica, bem como nos discursos hegemônicos e aterrorizantes que permeiam este cenário, propiciando novos olhares para usuários de drogas e seus familiares. Da mesma forma, é importante iniciar um movimento de desconstrução da imagem cruel e superficial que circula a existência do sujeito usuário de drogas, demonstrando que, muito além do uso de drogas, este sujeito habita um corpo repleto de singularidades e possibilidades de vida.

(Re)inscrever sentidos no cenário social contemporâneo sobre a temática da drogadição, sem dúvida, nos remete a possibilidade de contextualizar as dimensões sociais, históricas, econômicas e singulares envolvidas neste espaço. É necessário, abrir mão do olhar moralizador, e culpabilizante, para então construir uma pratica de cuidado e atenção especializada, responsável e comprometida com o sujeito usuário, sua família e a comunidade que o cerca. É importante considerar a implicação dos diversos fatores constituintes, inclusive, do papel do Estado na garantia de direitos sociais, civis e protetores da sociedade. 


\section{REFERÊNCIAS}

ARAUJO, B. R.; ZACHARIAS, D. G.; GARCIA, E. O Crack em Redes Discursivas: evidenciando concepções e problematizando práticas de enfrentamento. Revista Jovens Pesquisadores. Santa Cruz do Sul, v. 3 n. 1, EDUNISC, 2013. Disponível em: http://online.unisc.br/seer/index.php/jovenspesquisadores/article/view/3572/2671. Acesso em: 02 mar. 2015.

ARIÈS, P. História social da criança e da família. 2. ed. Rio de Janeiro: LTC, 1981.

CAVALCANTI, S. A. U.; VIEIRA, G. T. S. Ensaio sobre família, crack e Políticas Sociais no Brasil. In: V Jornada Internacional de Políticas Públicas, 2011, São Luís. Disponível em: http://www.joinpp.ufma.br/jornadas/joinpp2011/CdVjornada/JORNADA_EIXO_2011/ESTA DO_LUTAS_SOCIAIS_E_POLITICAS_PUBLICAS/ENSAIO_SOBRE_FAMILIA_CRAC K_E_POLITICAS_SOCIAIS_NO_BRASIL.pdf. Acesso em: 05 mar. 2015.

CONTE, M. A clínica psicanalítica com toxicômanos: o "corte \& costura" no enquadre institucional. 1. ed. Santa Cruz do Sul: EDUNISC, 2003.

DUARTE, P. C. A. V.; STEMPLIUK, V. A.; BARROSO, L. P. (Orgs.). Relatório Brasileiro Sobre Drogas. Secretaria Nacional de Políticas sobre Drogas. Brasília: SENAD, 2009. Disponível em: http://www.obid.senad.gov.br/portais/OBID/biblioteca/documentos/Relatorios/328379.pdf.

Acesso em: 18 fev. 2015.

GARCIA, E. L. et al. (Re)conhecendo o perfil do usuário de crack de Santa Cruz do Sul. Barbarói, Santa Cruz do Sul, Edição especial, v. 36, p. 83-95, jan./jun. 2012. Disponível em: https://online.unisc.br/seer/index.php/barbaroi/article/viewFile/2922/2106. Acesso em: 20 nov. 2014.

GARCIA, E. L. et al. Recaídas na drogadição: uma via para (re)pensar a atenção à saúde. Saúde em Debate (CEBES), Rio de Janeiro, n. edição especial, v. 37, p. 137-146, dez. 2013(a). Disponível em: http://cebes.com.br/site/wpcontent/uploads/2014/06/RSD_EspecialDrogas_REV2905_Web.pdf. Acesso em: 20 fev. 2015 .

GARCIA, E. L. et al. Entre a alienação de familiares de usuários de crack e os riscos do pesquisador. Barbarói, Santa Cruz do Sul, v. 39, p. 13-35, 2013 (b). Disponível em: http://online.unisc.br/seer/index.php/barbaroi/article/view/2031/3050. Acesso em: 20 fev. 2015.

MELMAN, C. Alcoolismo, delinquência, toxicomania: uma outra forma de gozar. São Paulo: Escuta, 1992.

NARVAZ, M. G.; KOLLER, S. H. Famílias e patriarcado: da prescrição normativa à subversão criativa. Psicologia \& Sociedade, Porto Alegre, n. 1, v. 18, p. 49-55, jan./abr. 2006.

RODRIGUES, L.; GUARESCHI, N. M. F.; CRUZ, L. R. A centralidade do vínculo familiar e comunitário nas políticas públicas de assistência social. In: CRUZ, L.; RODRIGUES, L.; 
GUARESCHI, N. M.(Orgs.). Interlocuções entre a Psicologia e a Política Nacional de Assistência Social. Santa Cruz do Sul: EDUNISC, 2013. p. 11-22.

SCHENKER, M.; MINAYO, M. C de S. A importância da família no tratamento do uso abusivo de drogas: uma revisão da literatura. Cadernos de Saúde Pública, Rio de Janeiro, n. 3, v. 20, p. 649-659, maio/jun. 2004. Disponível em: <http://www.scielo.br/pdf/csp/v20n3/02.pdf>. Acesso em: 03 mar. 2015.

SCHEINVAR, E. A família como dispositivo de privatização do social. Arquivos Brasileiros de Psicologia, Rio de Janeiro, n. 1, v. 58, p. 48-57, jun. 2006.

SPINK, M. J. P. (Org.). Práticas discursivas e produção de sentidos no cotidiano: aproximações teóricas e metodológicas. 2. ed. São Paulo: Cortez, 2000.

ZEFERINO, M. T. et al. Consumo de Drogas entre Estudantes Universitários: família, espiritualidade e entretenimento moderando a influência dos pares. Texto contexto - enferm., Florianópolis, v. 24, n. $\quad$ spe, p. 125-135, 2015. Disponível em: $<$ http://www.scielo.br/scielo.php?script=sci_arttext\&pid=S0104-

07072015000600125\&lng=pt\&nrm=iso>. Acesso em: 03 mar. 2015. 